\title{
Notice of inadvertent duplicate publication: Statin-induced apoptosis of vascular endothelial cells is blocked by dexamethasone
}

\author{
C J Newton, G Ran, Y X Xie, D Bilko, C H Burgoyne ${ }^{1}$, I Adams ${ }^{1}$, \\ A Abidia' ${ }^{2}$, P T McCollum² and S L Atkin
}

Jacob's Well Medical Research Laboratory, ${ }^{1}$ Diabetes and Endocrinology and ${ }^{2}$ Vascular Surgery, Hull and York Medical School, University of Hull, Cottingham Road, Hull HU6 7RX, UK

(Requests for offprints should be addressed to C J Newton; Email: CJNewton@Compuserve.com)

The journal wishes to draw attention to a paper by $\mathrm{C} \mathrm{J}$ Newton et al., 'Fluvastatin induces apoptosis of vascular endothelial cells: blockade by glucocorticoids', published in Cardiovascular Surgery 200311 52-60, that bears close similarity to the above titled article by the same authors first published in Journal of Endocrinology 2002 174 7-16.

These two articles are identical apart from the order of the authors and very minor changes in the figures and text, and we are therefore compelled to formally declare this as a case of inadvertent duplicate publication.
The article submitted to Journal of Endocrinology was accepted on 19 March 2002 and copyright was assigned on 22 April 2002. The duplicate article was accepted in Cardiovascular Surgery on 30 April 2002. It appears that the duplicate submission arose through a misunderstanding between the authors. Both they and Cardiovascular Surgery have expressed that there was no intention to knowingly publish the same material twice, and apologize for the error that is in contravention of our instructions to authors and of internationally agreed guidelines. 
